\title{
Dorsal Intramedullary Epidermoid Cyst: Report of Two Rare Cases and Review of Literature
}

\author{
Basanta Kumar Baishya ${ }^{1}$ Deep Dutta ${ }^{1}$ Asman Ali $^{1}$ Zakir Hussain ${ }^{1}$ \\ ${ }^{1}$ Department of Neurosurgery, Gauhati Medical College, Guwahati, \\ Assam, India \\ Address for correspondence Deep Dutta, MBBS, MS, Department of \\ Neurosurgery, Gauhati Medical College, Guwahati, Assam, India \\ (e-mail: duttadeep2844@yahoo.co.in).
}

Indian J Neurosurg 2016;5:40-43.

Abstract
Keywords
- dorsal
- spinal intramedullary
- epidermoid cyst

Study Design A report on two rare cases of dorsal intramedullary spinal epidermoid cyst.

Objective Clinical presentation, diagnosis, and surgical outcome of the two cases are discussed.

Case Description We report two cases of dorsal intramedullary epidermoid cyst, both presenting with descending spastic upper motor neuron type of paraparesis with pain and paresthesia of the lower limbs and early involvement of bladder and bowel. Magnetic resonance imaging was done to come to a diagnosis where the first case was having a dorsal intramedullary epidermoid cyst at D6-D7 and the second case has an epidermoid cyst at D5-D6 intravertebral level.

Results Near-total excision of the tumor was done in both the patients under microscope. Histopathologic examination confirmed the tumor as epidermoid. There was gradual neurologic improvement in both the cases on follow-up.

Conclusion Cases presenting with dorsal myelopathy without spinal dysraphism may be due to rare causes such as epidermoid cyst, and near-total excision of such cyst with microneurosurgical technique can give a good outcome.

\section{Introduction}

Epidermoid cyst is a benign tumor. ${ }^{1}$ They are pearly white in color with flaky materials without dermal appendages as in dermoid, first named and described by Cruveilhier in 1835 as tumeurs perlees. ${ }^{2,3}$ They constitute only 0.6 to $1.1 \%$ of all spinal cord tumors. ${ }^{4}$ Here we report two cases both of dorsal intramedullary epidermoid tumors, without spinal dysraphism. Detail clinical features and their management are discussed with relevant review of literatures.

\section{Case 1}

A 60-year-old man presented with 1-year history of pain and paresthesia of right lower limb with spastic upper motor neuron type of paraparesis and 6 months history of urinary incontinence. On examination the patient had increased tone over both the lower limbs with a power of 3/5 bilaterally. The patient had diminished pain and temperature sensation below D6 vertebral level over the right side and over the left side his sensation was intact. Sacral sensation was impaired over the right side. Anal tone was normal. His deep tendon reflexes were exaggerated and he had ill-sustained ankle clonus bilaterally. His position sense was impaired below knee bilaterally. His abdominal reflexes were absent in all four quadrants. His planters were up going bilaterally. He was catheterized on admission.

His magnetic resonance imaging (MRI) showed an intramedullary mass lesion with an exophytic intradural component from D6 vertebral to D6-D7 disc level. The intramedullary component was hyperintense on T2-weighted images and iso- to subtle hypointense on
License terms of India received

October 8, 2015

accepted

November 18, 2015

published online

February 24, 2016
DOI http://dx.doi.org/

$10.1055 / \mathrm{s}-0036-1572381$ ISSN 2277-954X. 
T1-weighted imaging. There was no demonstrable contrast enhancement ( - Fig. 1A-D).

\section{Differential Diagnosis: Arachnoid Cyst, Astrocytoma, Ependymoma, Epidermoid Cyst}

The patient underwent D6 to D7 laminectomy. The dura was tense and bulging where the incision was made. The cord was thickened and expanded with some part of the mass seen bulging and making that part of the cord parenchyma thinned out. Then we proceeded with a midline myelotomy over the most bulging part. The tumor was seen avascular with soft cheesy material that was suckable. There was a calcified part attached with the capsule. We plugged the subarachnoid space both proximally and distally to avoid spillage. Near-total excision of the tumor was performed leaving behind the capsule that was adherent to the cord parenchyma. Then we irrigated with normal saline, and after achieving total hemostasis, we closed the wound layer by layer.

Histopathology confirmed the diagnosis of epidermoid cyst (- Figs. 2 and $\mathbf{3}$ ).

On follow-up, after physiotherapy and rehabilitation the patient improved neurologically, and at present he can walk with support with minimal spasticity, but his urinary incontinence persisted.

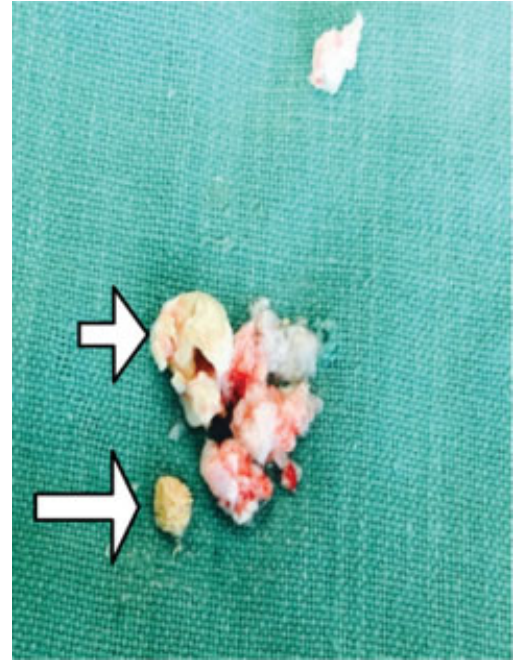

Fig. 2 Image showing the gross appearances of the tumor mass after excision. Arrow showing the calcified part.

\section{Case 2}

A 20-year-old woman presented with 2 years history of pain and paresthesia over her left thigh with progressive

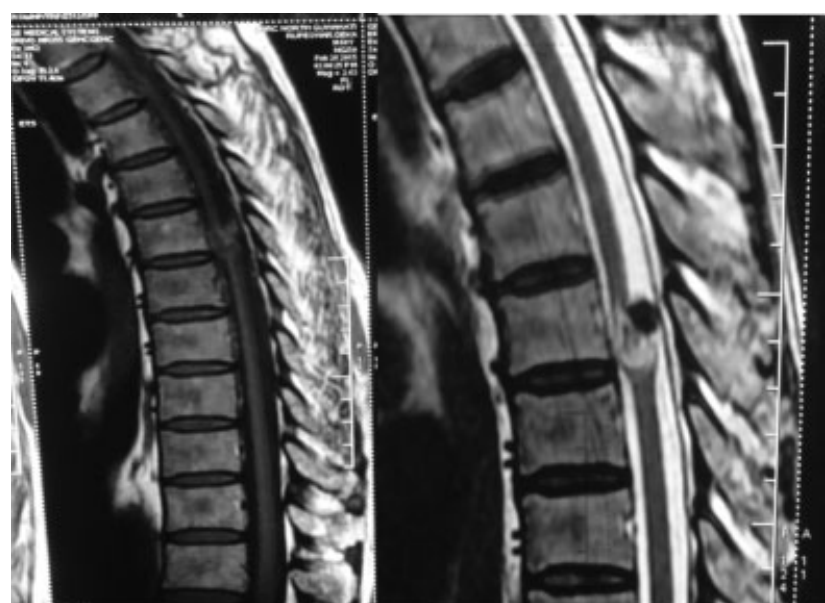

A

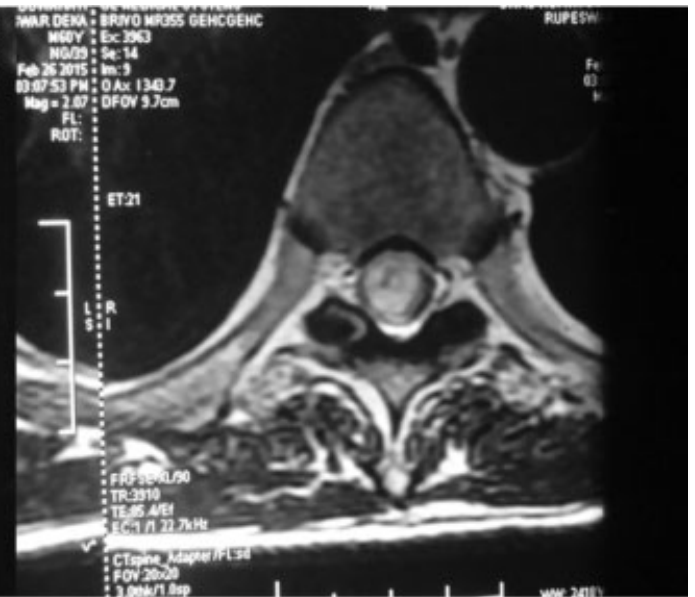

C

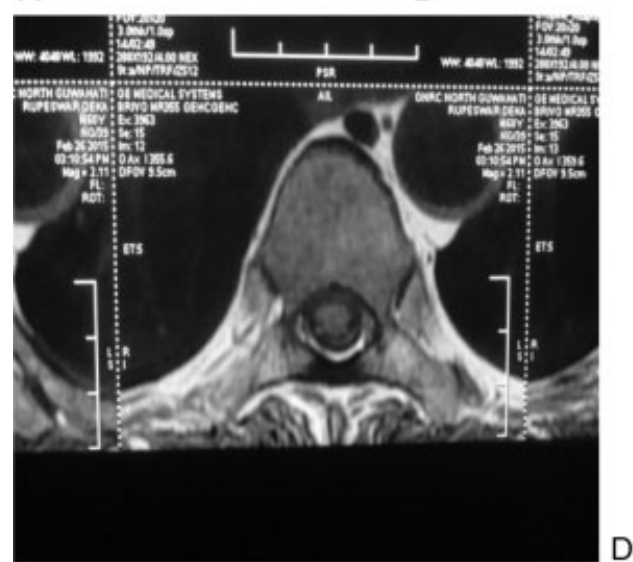

Fig. 1 MR images showing an intramedullary mass lesion with an exophytic intradural component seen from D6 vertebral to D6-D7 disc level. (A) Showing T1 hypointense intramedullary mass lesion in saggital image. (B) Showing T2 hyperintense intramedullary part with a intradural extramedullary hypointense part in a saggital view. (C) Showing axial image where mild enhancement of the intramedullary mass seen with contrast. (D) Axial image showing the intramedullary lesion that appears iso to subtle hypointense on T1-weighted image. 


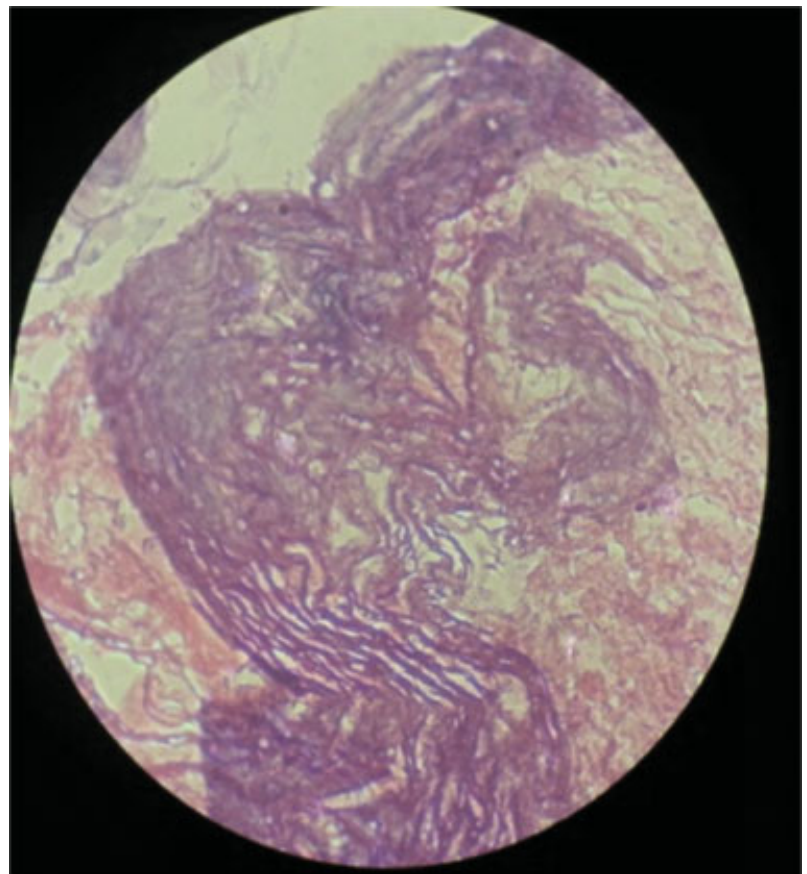

Fig. 3 Histopathologic image showing stratified squamous epithelium with an outer collagenous tissue with keratin from the desquamated epithelium in the interior of the cyst that contains cheesy, soft, whitish material. spastic upper motor neuron type of paraparesis. The patient had 1-year history of urinary disturbances in the form of urgency and incontinence. She was catheterized on admission. Clinical examination revealed spastic upper motor type of paraparesis with power of grade $4 / 5$ on the left side and $3 / 5$ on the right side. Abdominal reflexes were absent in all four quadrants. Diminution of pin prick and temperature sensation below D6 was noted over the left side and position sense was impaired below the knee over the left side and below the ankle over the right side. Vibration sense was impaired below D5 vertebra. Sacral sensation was impaired. Increased tones over the lower limbs were found with exaggerated knee and ankle jerks and ill-sustained clonus. Local examination of the spine did not reveal any spinal dysraphic, cutaneous lesions such as hair, sinus, fistula, or dimples.

Her MRI revealed T1 hypointense and T2 hyperintense signal intensity lesion having intra- and extramedullary components at D5 and D6 vertebral levels with diffusion restriction suggestive of epidermoid. The lesion measures $2.1 \times 1.3 \mathrm{~cm}$ in size. No demonstrable contrast enhancement was seen (-Fig. 4A-D).

A D5 to D6 laminectomy was performed. On incising the dura, a whitish mass was seen subpially with bulge of the cord parenchyma. We proceeded under microscope, and on dissecting the arachnoid layer, the pearly mass seen, which was capsulated. On further dissection the cheesy material could be removed completely under the capsule. It was avascular. We could remove some part of the capsule. After

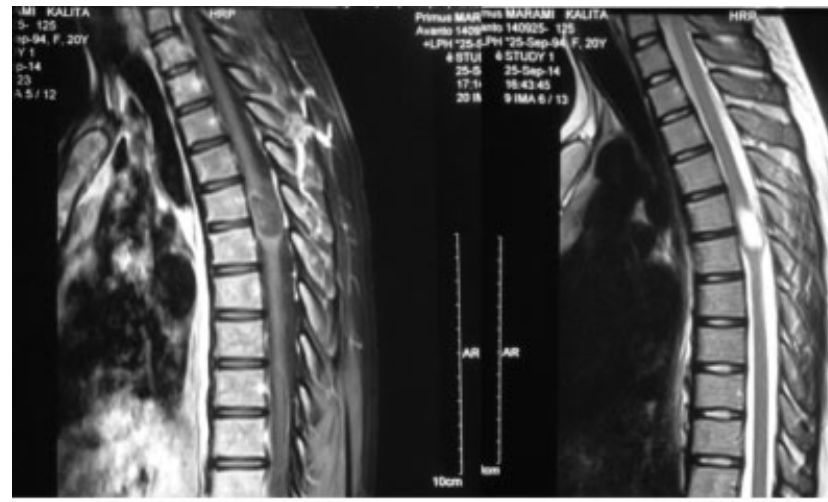

A

B

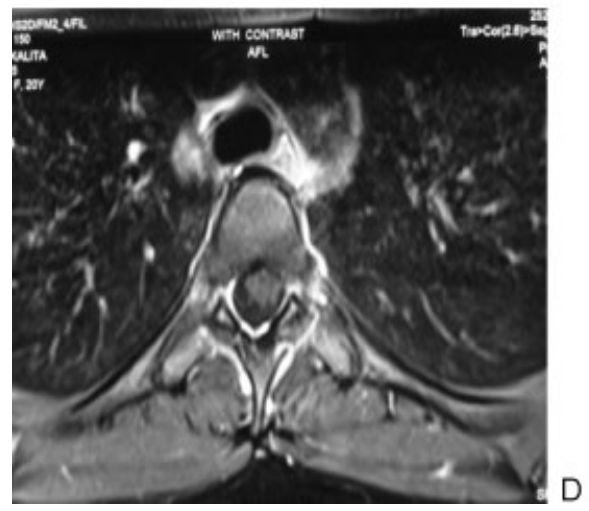

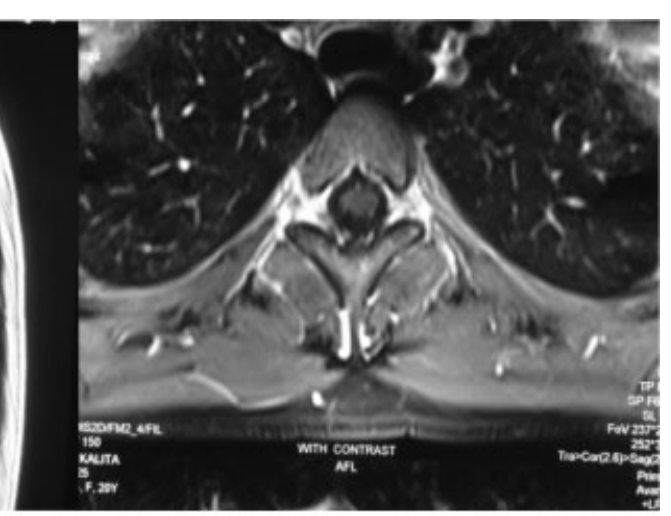

C

Fig. 4 MR images reveals T1 hypointense (A) and T2 hyperintense (B) lesion having intra- and extramedullary components at D5 and D6 vertebral levels with diffusion restriction on diffusion restriction axial images as shown in (C and D). 


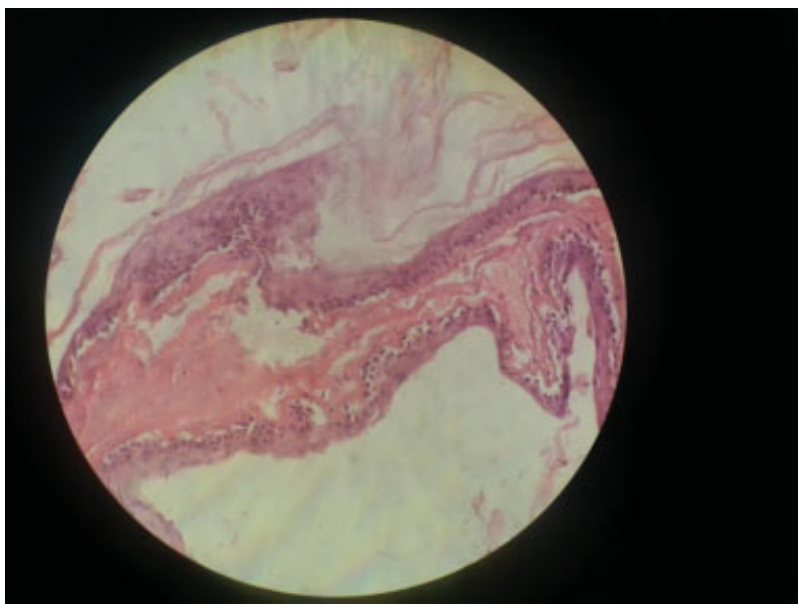

Fig. 5 Histopathologic image showing stratified squamous epithelium with an outer collagenous tissue with keratin from the desquamated epithelium in the interior of the cyst consistent with epidermoid.

proper saline irrigation and hemostasis, the dura was closed water tightly and the wound was closed in layers. Histopathology confirmed the diagnosis of benign epidermoid tumor (-Fig. 5).

Postoperatively patient improved and on follow-up she was ambulatory with a power of $4 / 5$ with minimal spasticity in both the lower limbs. There was no pain and paresthesia although urinary incontinence persisted.

\section{Discussion}

Spinal epidermoid tumor may be congenital or acquired. Whereas congenital epidermoid cysts that are more common originates from displaced ectodermal inclusions during early fetal life and also associated with defective closure of the neural tube, ${ }^{5}$ acquired epidermoid cysts are following lumbar puncture or any penetrating spinal injury.

Intramedullary epidermoid tumors are very rare. First case was reported by Chiary in $1833 .^{6}$ In 1989 , Roux et al reviewed and collected 46 patients from literature and added one of his own case. ${ }^{5}$ Since then there have been scattered case reports.

Associated overlying bony deformity or dysraphic cutaneous lesions such as hair, sinus, fistula, or dimples 5 may be present. These may lead to infection and the patient may present with meningitis.

Mostly symptoms and signs are directly associated with the size and site of the tumor as seen in our cases.

MRI is an effective tool for the diagnosis. Epidermoid cyst is iso- or slightly hyperintense compared with cerebrospinal fluid (CSF) on both T1- and T2-weighted sequences. Slight heterogeneity in signal intensity is often present. Epidermoid cyst does not suppress at all or suppress incompletely on FLAIR (fluid-attenuated inversion recovery). They resist on diffusion-weighted imaging (DWI) and are therefore moderately to strikingly hyperintense. ${ }^{7,8}$ Spinal epidermoid cysts are very rare tumors that can be incorrectly diagnosed as arachnoid cysts, especially when iatrogenic and presenting in an adult with no evidence of spine malformations or other dysraphic defects. Because of the high signal presented by epidermoid tumors, DWI is very helpful to identify and differentiate them. DWI can also be useful for postoperative follow-up of these lesions, especially if not completely removed. ${ }^{8}$

The surgical goal is complete excision. Most of the authors reported total excision, and we too did near-total excision and got a good result. ${ }^{8-10}$ Total excision of the tumor has lot of high risk as the tumor capsule is adherent with the cord parenchyma. Even partial excision results in total remission of symptoms ${ }^{5,6}$ although there is always a risk of tumor recurrence. $^{6}$

Operative complications may include damage to the neurovascular structures and lead to sphincter disturbances. Aseptic chemical meningitis is unique to epidermoid lasting for weeks, if severe, and can lead to arachnoiditis. By plugging of proximal and distal arachnoid space prior to tumor resection in both our cases and by irrigating and washing the site with normal saline prior to dural closure, we have reduced the chances of spillage of epidermoid that may lead to chemical meningitis. 9,10

Conflict of Interest

None.

\section{References}

1 Von Bostroem E. Ueber die piialen Epidermoide. Dermoide und Lipome duralen Dermoide. Zentralbl Allg Pathol 1897;8:1-98

2 Cruveilhier J. Anatomie Pathologique. Vol. 2. Paris, France: Bailliere JB; 1835

3 Zavanone M, Guerra P, Rampini PM, Crotti F, Vaccari U. A cervicodorsal intramedullary epidermoid cyst. Case report and review of the literature. J Neurosurg Sci 1991;35(2):111-115

4 Lunardi P, Missori P, Gagliardi FM, Fortuna A. Long-term results of the surgical treatment of spinal dermoid and epidermoid tumors. Neurosurgery 1989;25(6):860-864

5 Roux A, Mercier C, Larbrisseau A, Dube LJ, Dupuis C, Del Carpio R. Intramedullary epidermoid cysts of the spinal cord. Case report. J Neurosurg 1992;76(3):528-533

6 Chandra PS, Manjari T, Devi BI, Chandramouli BA, Srikanth SG, Shankar SK. Intramedullary spinal epidermoid cyst. Neurol India 2000;48(1):75-77

7 Penisson-Besnier I, Guy G, Gandon Y. Intramedullary epidermoid cyst evaluated by computed tomographic scan and magnetic resonance imaging: case report. Neurosurgery 1989;25(6): 955-959

8 Manzo G, De Gennaro A, Cozzolino A, Martinelli E, Manto A. DWI findings in a iatrogenic lumbar epidermoid cyst. A case report. Neuroradiol J 2013;26(4):469-475

9 Mishra SS, Satapathy MC, Deo RC, Tripathy SR, Senapati SB. Isolated thoracic (D5) intramedullary epidermoid cyst without spinal dysraphism: a rare case report. J Pediatr Neurosci 2015; 10(2):133-136

10 Gotecha S, Ranade D, Sharma S, Punia P, Kotecha M. Giant intradural intramedullary epidermoid cyst: report of two cases with varied presentations. Asian J Neurosurg 2014; $9(4): 244$ 